\title{
Aktivasi dan Aplikasi Zeolit Alam Sebagai Adsorben Logam Kromium Dalam Air Limbah Industri Penyamakan Kulit
}

\section{Activation and Application of Natural Zeolite for Adsorbent of Chromium in Wastewater of Leather Industry}

\author{
Lucky Wahyu Nuzulia Setyaningsih ${ }^{\mathrm{a}^{*}}$, Zahra Ike Asmira, Nadhya Chairiza Fitri W \\ a Jurusan Teknik Kimia, Fakultas Teknologi Industri, Universitas Islam Indonesia \\ Jalan Kaliurang Km. 14,5 Sleman, Yogyakarta 55501, Indonesia
}

\section{Artikel histori :}

Diterima Mei 2017 Diterima dalam revisi Juli 2017 Diterima Agustus 2017 Online September 2017

\begin{abstract}
ABSTRAK: Industri penyamakan kulit menghasilkan limbah cair dengan jumlah yang cukup besar dan mengandung logam berat kromium yang bersifat non-biodegradable sehingga keberadaanya di lingkungan akan terakumulasi hingga mencapai kadar yang berbahaya bagi lingkungan dan manusia. Salah satu metode untuk menangani masalah ini adalah adsorpsi dengan memanfaatkan zeolit alam sebagai adsorben. Zeolit alam dipilih karena memiliki potensi sebagai penjerap dan keberadaanya di alam cukup melimpah. Variasi metode aktivasi dengan pemanasan dan penambahan larutan $\mathrm{KOH}$ sebagai aktivator dengan konsentrasi $2 \mathrm{M}$, 4M, 6M akan diuji untuk meningkatkan kemampuan penjerapan. Metode aktivasi secara kimia menggunakan konsentrasi $\mathrm{KOH} 6 \mathrm{M}$ memberikan presentase penjerapan paling baik dengan daya serap terhadap kromium sebesar $12,1065 \mathrm{mg} / \mathrm{g}$. Pengujian model Isotherm yang mewakili proses adsorpsi ini adalah Model Freundlich.
\end{abstract}

Kata Kunci: Adsorpsi, Kromium, Zeolit, Limbah Cair, Penyamakan Kulit

\begin{abstract}
The leather industry produces large quantities of liquid waste contains nonbiodegradable metals, chromium. The accumulation chromium produced from leather industry will harmfull the environment and humans. One method to deal with this problem is adsorption process by utilizing natural zeolite as an adsorbent. Natural zeolite is chosen because it has the potential as an absorbent and its existence in nature is quite abundant. Variations of activation methods with heating and addition of $\mathrm{KOH}$ solution as activators with concentrations of $2 \mathrm{M}$, $4 \mathrm{M}, 6 \mathrm{M}$ will be tested to improve the ability of adsorption. The chemical activation method using $\mathrm{KOH} 6 \mathrm{M}$ concentration gives the best adsorption percentage with absorbency to chromium of $12.1065 \mathrm{mg} / \mathrm{g}$. The result indicate that this adsorption process is following Freundlich Model.
\end{abstract}

Keywords: Adsorption, Chromium, Zeolite, Liquid Waste, Leather Industry

\section{Pendahuluan (Introduction)}

Salah satu komponen yang terkandung dalam limbah cair industri penyamakan kulit adalah kromium. Kromium termasuk dalam logam berat yang bersifat nonbiodegradable atau tidak dapat terurai, sehingga keberadaanya di lingkungan akan terakumulasi hingga mencapai kadar yang berbahaya bagi lingkungan. Paparan logam berat terhadap manusia menjadi berbahaya meskipun dalam kadar yang rendah dan menyebabkan kelainan pada sistem otak, ginjal dan saraf. Logam kromium banyak dihasilkan pada limbah cair industri penyamakan kulit yang berasal dari bahan penyamak yang digunakan yaitu kalium dikromat $\left(\mathrm{K}_{2} \mathrm{Cr}_{2} \mathrm{O}_{7}\right)$. Industri penyamakan kulit menghasilkan limbah cair dalam kuantitas yang cukup banyak mengingat kebutuhan air dalam proses penyamakan sangat besar, terlebih air merupakan kebutuhan utama manusia, sehingga kontaminasi kromium pada air perlu dihindari.

Salah satu metode yang dapat digunakan untuk memisahkan logam kromium dari limbah cair industri penyamakan kulit adalah metode adsorpsi. Pada penelitian ini akan dilakukan penjerapan kromium menggunakan zeolit alam sebagai adsorben. Zeolit alam dipilih karena memiliki potensi sebagai penjerap dan keberadaanya di alam cukup melimpah. Untuk meningkatkan kemampuan penjerapan, zeolit alam akan diaktivasi secara fisika dan kimia. Proses adsorpsi akan dilakukan menggunakan sistem batch untuk mendapatkan kurva kesetimbangan. Melalui 
kurva kesetimbangan isotermis maka jumlah adsorbat yang terjerap pada adsorben dapat ditentukan. Pada penelitian ini juga akan dievaluasi pengaruh proses aktivasi adsorben terhadap proses adsorpsi. Hasil penelitian yang diperoleh diharapkan dapat memberikan kontribusi informasi tentang kondisi optimum yang dapat dipakai dalam metode adsorpsi logam kromium dari limbah cair industri kulit serta dapat memberikan metode alternative dalam mengatasi permasalahan lingkungan yang disebabkan karena limbah cair industri penyamakan kulit dengan memanfaatkan zeolit alam sebagai adsorben.

\subsection{Aktivasi Adsorben}

Salah satu karakteristik utama dari adsorben adalah memiliki permukaan aktif yang mampu menjerap partikel adsorbat. Oleh karena itu, adsorben perlu diaktivasi terlebih dahulu sebelum digunakan guna mengoptimalkan kemampuan adsorpsinya. Pengaruh aktivasi baik secara fisika dan kimiawi diteliti oleh Sholeh (2013) terhadap abu terbang bagas. Abu terbang bagas diaktivasi secara fisika melalui proses pemanasan pada suhu $100^{\circ} \mathrm{C}$ selama 24 jam, sedangkan secara kimiawi abu terbang bagas diaktivasi menggunakan larutan $\mathrm{H}_{2} \mathrm{O}_{2}$ dan larutan $\mathrm{H}_{2} \mathrm{SO}_{4}$. Penjerapan terbaik didapatkan dari abu terbang bagas dengan aktivasi fisika dibanding dengan aktivasi secara kimia. Sedangkan pengaruh perbandingan konsentrasi larutan aktivator pada proses aktivasi abu dasar ampas tebu diteliti oleh Suhendarwati. Abu dasar ampas tebu diaktivasi secara kimiawi menggunakan larutan $\mathrm{KOH}$ dengan konsentrasi $1 \mathrm{M}, 2 \mathrm{M}, 3 \mathrm{M}, 4 \mathrm{M}$ dan 5M. Metode aktivasi dengan konsentrasi $\mathrm{KOH}$ 5M menghasilkan karakteristik abu yang lebih mendekati standar mutu karbon aktif dengan daya serap terhadap iodin sebesar $426 \mathrm{mg} / \mathrm{g}$ dan daya serap terhadap methylene blue sebesar $21,04 \mathrm{mg} / \mathrm{g}$. Perlakuan aktivasi secara refluk untuk mengetahui pengaruh konsentrasi $\mathrm{HCl}$ dan rasio fly ash / $\mathrm{NaOH}$ terhadap daya serap fly ash yang terbentuk menunjukkan bahwa adsorben fly ash dapat menjerap logam besi sebesar 4,97 mg/g pada kondisi rasio $\mathrm{FA} / \mathrm{NaOH} 1,2$ dan konsentrasi $\mathrm{HCl} 7 \mathrm{M}$ (Novia, 2012).

\subsection{Isotherm Adsorpsi}

Isotherm adsorpsi menggambarka distribusi molekul adsorbat di fase padatan dan di fase fluida ketika proses adsorpsi mencapai kesetimbangan. Isotherm adsorpsi pentung digunakan untuk mengetahui kondisi optimum penggunaan adsorben. Pengujian model kesetimbangan isotherm dilakukan dengan pendekatan menggunakan model isotherm Langmuir dan Freundlich. Penentuan model isotherm dilihat dari harga koefisien determinan $\left(\mathrm{R}^{2}\right)$ yang lebih tinggi. Jumlah logam yang terjerap di dalam adsorben dapat dihitung dengan persamaan sebagai berikut: $q_{e}=\frac{\nabla}{m}\left(C_{0}-C_{\theta}\right)$

Model Isotherm Langmuir mengasumsikan bahwa adsorbat yang terjerap tidak dapat bergerak dipermukaan adsorben dan tidak saling bereaksi. Permukaan adsorben hanya mampu menjerap satu molekul adsorbat akibat dari seluruh permukaan adsorben memiliki afinitas yang sama terhadap adsorbat (Do,1988). Persamaan Langmuir dapat dituliskan dengan persamaan berikut (Aksu dan Gonen, 2004):

$q_{e}=\frac{Q^{\mathrm{D}} b c_{\mathrm{g}}}{1+b c_{\mathrm{g}}}$

Sedangkan pada model isotherm Freundlich menggunakan asumsi bahwa permukaan adsorben bersifat heterogen, sehingga memiliki afinitas yang berbeda-beda di setiap bagian permukaan. Persamaan Freundlich dapat ditulis dengan persamaan berikut:

$q_{e}=K_{F} C_{e}^{1 / n}$

Dengan,

$q_{e}$ adalah Kandungan logam dalam zeolit yang berada pada kesetimbangan, mg/g

$\mathrm{C}_{\mathrm{e}}$ adalah Konsentrasi logam yang berada pada kesetimbangan, $\mathrm{mg} / \mathrm{L}$

$Q^{0}$ merepresentasikan sebagai kandungan logam dalam zeolit yang membentuk lapisan monolayer komplit, $\mathrm{mg} / \mathrm{g}$

b merepresentasikan sebagai konstanta terkait dengan afinitas binding sites, $\mathrm{L} / \mathrm{mg}$

$\mathrm{K}_{\mathrm{F}}$ merupakan konstanta persamaan Freundlich, $(\mathrm{mg} / \mathrm{g}) /(\mathrm{L} / \mathrm{mg})^{1 / \mathrm{n}}$

$\mathrm{N}$ merupakan konstanta persamaan Freundlich

$\mathrm{V}$ adalah volume larutan limbah, $\mathrm{L}$

$\mathrm{m}$ adalah massa adsorben yang digunakan, $\mathrm{g}$

\section{Metode Penelitian}

\subsection{Alat dan Bahan}

Bahan yang digunakan dalam penelitian ini adalah zeolit alam dan aquadest. Sedangkan alat penelitian yang digunakan antara lain erlenmeyer, magnetic stirer, termometer, corong kaca, dan kertas saring.

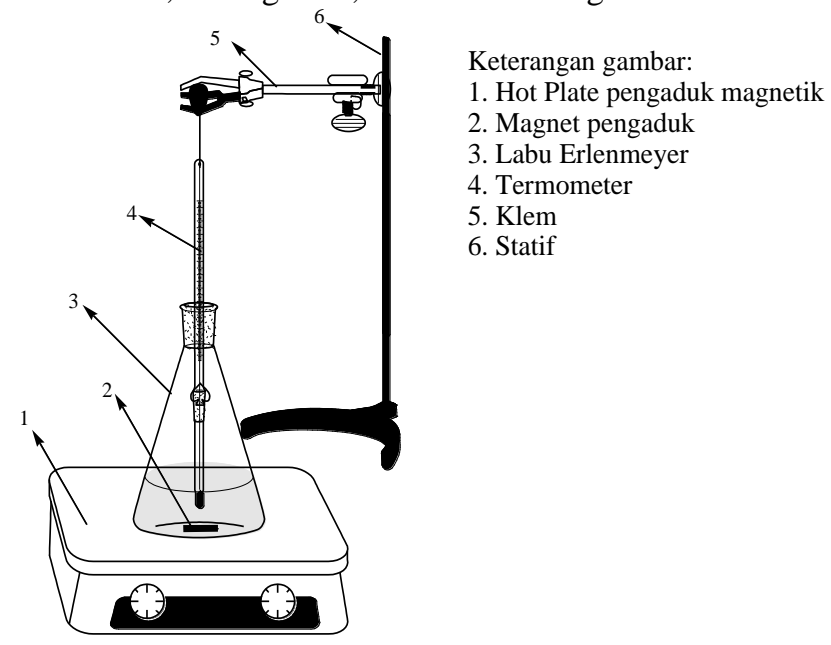

Gambar 1. Rangkaian Alat Adsorpsi Secara Batch

\subsection{Metode Penelitian}

Zeolit alam terlebih dahulu diaktivasi sebelum digunakan sebagai adsorben. Proses aktivasi dilakukan menggunakan 
2 cara yaitu secara fisis dan kimia. Aktivasi secara fisis, dilakukan dengan memanaskan zeolit dalam oven pada suhu $100^{\circ} \mathrm{C}$ selama 24 jam lalu disimpan dalam desikator. Sedangkan proses aktivasi secara kimia dilakukan dengan merendam zeolit alam di dalam $100 \mathrm{~mL}$ larutan $\mathrm{KOH}$ dengan konsentrasi 2M, 4M dan 6M selama 5 jam. Tahap selanjutnya, zeolit alam dikeringkan dalam oven pada suhu $60^{\circ} \mathrm{C}$ selama 24 jam lalu disimpan dalam desikator.

Air limbah sebanyak $50 \mathrm{~mL}$ dimasukkan ke dalam erlenmeyer dan diletakkan di atas magnetic stirer. Sebanyak 0,5 gram zeolit yang sudah diaktivasi dimasukkan ke dalam erlenmeyer bersamaan dengan itu pengaduk magnetic stirer dihidupkan dengan kecepatan skala 2. Adsorpsi berlangsung pada suhu kamar sampai tercapai kesetimbangan. Percobaan diatas diulangi untuk massa adsorben $5 \mathrm{~g} ; 8 \mathrm{~g}$; dan $10,0 \mathrm{~g}$.

\subsection{Analisa Hasil}

Analisa kadar crude oil setelah adsorpsi dilakukan menggunakan alat AAS (Atomic Adsorption Spectroscopy). Data yang diperoleh berupa konsentrasi logam di setiap waktu dengan variasi proses aktivasi dan massa adsorben. Data tersebut dibuat grafik antara konsentrasi logam dalam sample terhadap waktu, kemudian grafik untuk setiap proses aktivasi yang berbeda digabung untuk dapat dibandingkan pengaruhnya.

\section{Hasil dan Pembahasan}

\subsection{Pengaruh Massa Adsorben}

Pada Gambar 2 terlihat bahwa pada rentang massa 0,5 - 8 gram menunjukkan bahwa semakin besar massa adsorben yang digunakan maka konsentrasi logam kromium semakin menurun. Hal ini menunjukkan bahwa logam kromium yang terjerap semakin banyak.

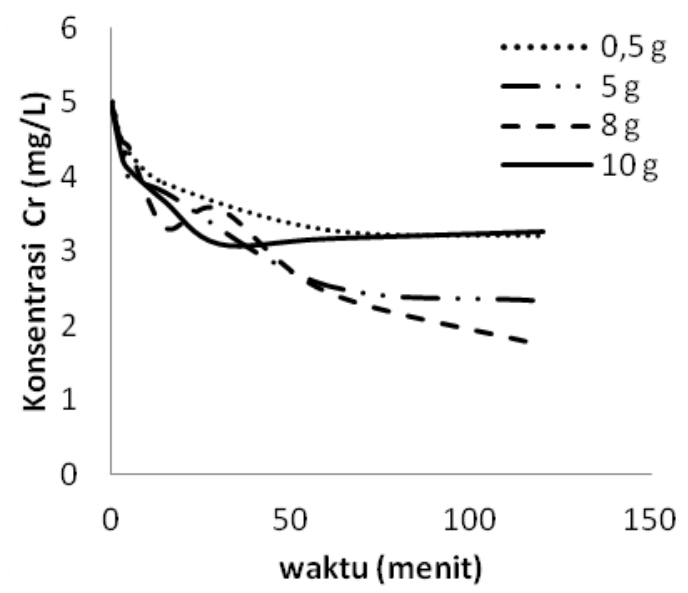

Gambar 2. Hasil Data Pengaruh Variasi Massa Adsorben pada Konsentrasi KOH 2M

Peristiwa ini disebabkan karena dengan bertambahnya massa adsorben maka luas bidang kontak dan situs aktif pada permukaan adsorben semakin besar, sehingga terjadi peningkatan penjerapan logam kromium ke dalam adsorben zeolit. Namun pada massa adsorben 10 gram, jumlah kromium yang terjerap semakin sedikit hal ini dapat disebabkan karena terjadinya tumpang tindih situs aktif sebagai akibat dari kepadatan jumlah partikel adsorben dalam sistem.

\subsection{Pengaruh Aktivasi Adsorben}

Hasil uji pengurangan logam kromium dengan zeolit alam pada berbagai variasi aktivasi untuk massa adsorben sebanyak 0,5 gram terlihat pada Gambar 3. Dari Gambar 3 terlihat bahwa antara aktivasi dengan bahan kimia dan aktivasi dengan pemanasan, terlihat bahwa presentase penurunan logam kromium terbesar diberikan oleh aktivasi secara kimia. Selain itu, terlihat bahwa dengan semakin besar konsentrasi $\mathrm{KOH}$ sebagai aktivator, maka presentase penurunan kromium semakin besar. Hal ini disebabkan karena $\mathrm{KOH}$ merupakan basa kuat yang berfungsi sebagai zat pengaktif yang akan mengikat senyawa-senyawa organik dalam zeolit sehingga akan memperluas permukaan aktif zeolit.

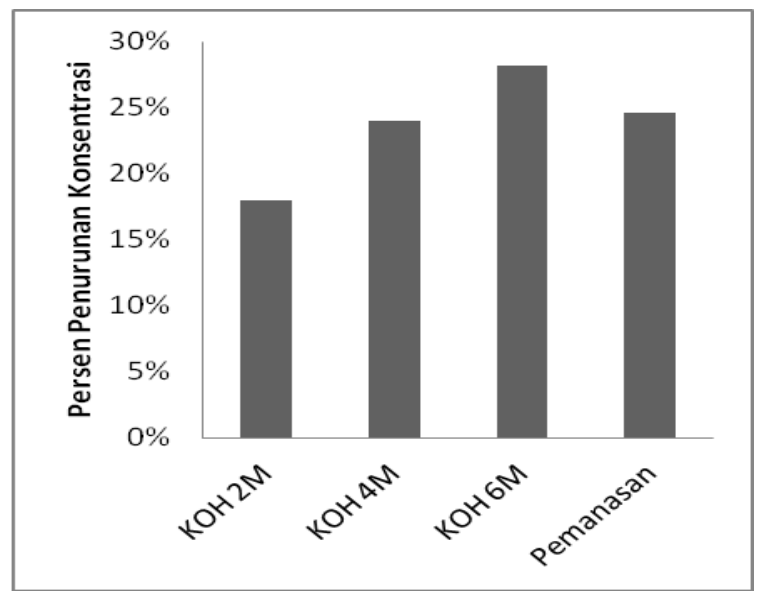

Gambar 3. Presentase Pengurangan Logam Kromium pada Berbagai Perlakuan Aktivasi Zeolit Alam dengan Massa Adsorben 0,5 gram

\subsection{Pengaruh Waktu Kontak Adsorpsi}

Gambar 4 menunjukkan pengaruh waktu kontak adsorpsi terhadap penurunan konsentrasi logam kromium. Pengujian pengaruh waktu kontak terhadap proses adsorpsi dilakukan selama 120 menit. Dari Gambar 4 terlihat bahwa untuk kedua jenis proses aktivasi baik secara kimia dan fisis dan untuk seluruh variasi konsentrasi larutan $\mathrm{KOH}$ sebagai aktivator menunjukkan kecenderungan yang sama. Dimana, semakin lama waktu kontak antara zeolit dan limbah cair, maka semakin banyak logam kromium yang terjerap. Hal ini disebabkan karena semakin lama waktu adsorpsi, maka kesempatan partikel zeolit untuk kontak dengan molekul logam semakin besar, sehingga logam kromium yang terjerap di dalam pori-pori zeolit semakin banyak.

Untuk seluruh variasi, konsentrasi logam kromium di dalam air limbah mengalami penurunan cukup tajam di awal waktu dan cenderung konstan setelah 15 menit, hal ini ditandai dengan grafik yang terbentuk di awal waktu cukup landai kemudian konstan. Hal ini menunjukkan bahwa 
proses adsorpsi terjadi secara cepat sehingga kondisi jenuh adsorben dicapai dalam waktu yang singkat. Grafik datar menunjukkan bahwa zeolit sudah mencapai kondisi jenuh, dimana sudah tidak mampu menjerap lagi logam kromium, sehingga tidak terjadi penurunan konsentrasi.

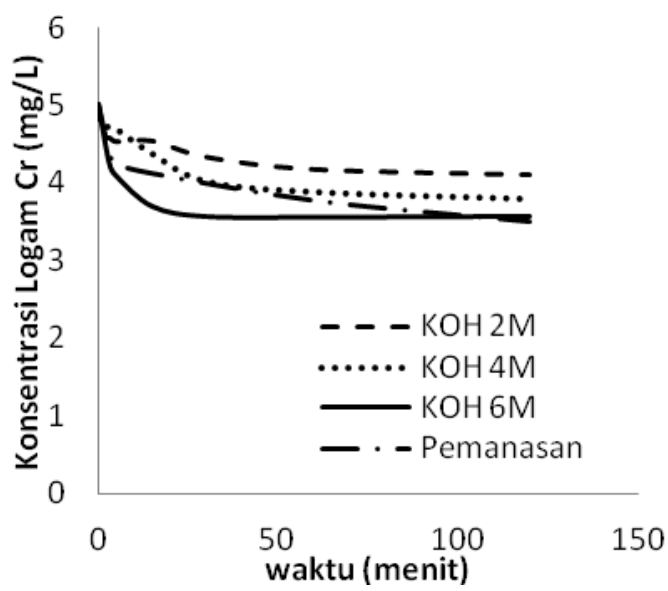

Gambar 4. Hubungan Waktu Kontak Adsorpsi terhadap Penurunan Konsentrasi Kromium dengan Massa Adsorben 0,5 gram

\subsection{Isotherm Adsorpsi}

Analisa isotherm dilakukan dengan pendekatan Model Langmuir dan Model Freundlich. Karakter isotherm adsorpsi dapat dilihat dari nilai konstanta yang mengindikasikan kapasitas adsorpsi, afinitas dan karakteristik permukaan adsorben. Konstanta untuk model kesetimbangan Langmuir, dan Freundlich yang diperoleh dari hasil perhitungan dapat dilihat pada Tabel 1 .

Tabel 1. Nilai Konstanta Persamaan Kesetimbangan

\begin{tabular}{ccc}
\multicolumn{3}{c}{ Adsorpsi Isotherm } \\
\hline Konstanta & Nilai & $\mathbf{R}^{2}$ \\
\hline$Q^{0}, \mathrm{mg} / \mathrm{g}$ & 12,1065 & \\
$\mathrm{~b}, \mathrm{~L} / \mathrm{mg}$ & 0,2441 & 0,6826 \\
Persamaan Freundlich & & \\
$K_{F},(\mathrm{mg} / \mathrm{g}) /(\mathrm{L} / \mathrm{mg})^{1 / \mathrm{n}}$ & 0,4842 & \\
$\mathrm{n}$ & & 0,6880 \\
& 0,2411 & \\
\hline
\end{tabular}

Perhitungan terhadap koefisien determinan $\left(\mathrm{R}^{2}\right)$ dari persamaan Freundlich menghasilkan nilai yang lebih besar dibanding persamaan Langmuir. Persamaan Freundlich lebih mewakili fenomena adsorpsi yang terjadi antara logam kromium dan zeolit alam sebagai adsorben. Dari persamaan Langmuir didapatkan kapasitas penjerapan maksimum zeolit alam dalam menjerap logam kromium sebesar $12,1065 \mathrm{mg} / \mathrm{g}$.

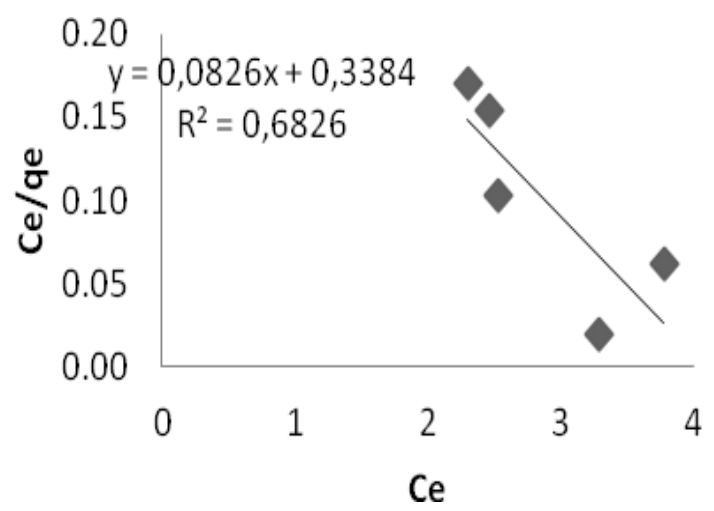

Gambar 4. Kurva Kesetimbangan Isotherm Adsorpsi Model Langmuir

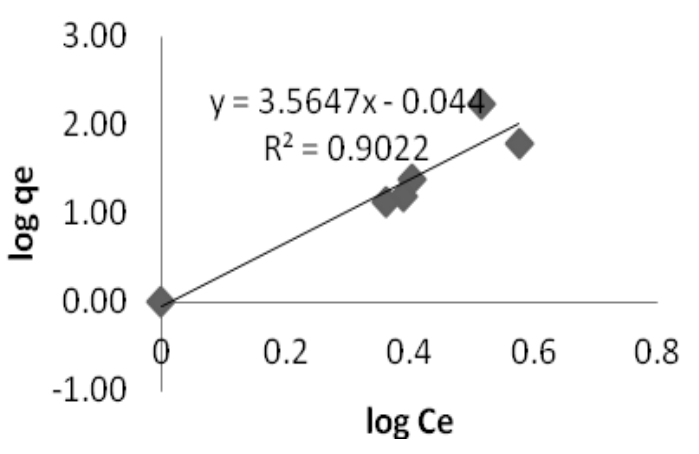

Gambar 5. Kurva Kesetimbangan Isotherm Adsorpsi Model Freundlich

\section{Kesimpulan}

Berdasarkan penelitian yang telah dilakukan, dapat diambil kesimpulan sebagai berikut:

1. Semakin besar massa adsorben yang digunakan maka konsentrasi logam kromium semakin menurun, dan semakin lama waktu kontak antara zeolit dan limbah cair, maka semakin banyak logam kromium yang terjerap.

2. Pengujian metode aktivasi secara kimia menggunakan larutan $\mathrm{KOH} 6 \mathrm{M}$ memberikan presentase penurunan logam kromium terbesar.

Adsorpsi logam kromium menggunakan zeolit alam teraktivasi mengikuti model isotherm Freundlich

\section{Daftar Pustaka}

Aksu, Z. dan Gonen, F., 2004, "Biosorption of Phenol by Immobilized Activated Sludge in a Continuous Packed Bed: Prediction of Breakthrough Curve", Process Biochemistry, Vol. 39, pp. 599-613.

Do, D. D., 1998, “Adsorption analysis : Equilibria and Kinetics”, Imperial College,London. 
Eksergi, Vol 14, No. 1. 2017

ISSN: $1410-394 \mathrm{X}$

Novia, dkk., 2012, "Pembuatan Adsorben dari Fly Ash Hasil Pembakaran Batubara untuk Mengadsorpsi Logam Besi (Fe)", Laporan Penelitian, Universitas Sriwijaya.

Sholeh, M., Prasetya, A., Sarto, 2013, Pemodelan Matematis Pengurangan COD dalam Air Limbah

Industri Penyamakan Kulit Secara Adsorpsi Kontinyu Menggunakan Abu Terbang Bagas", Majalah Kulit, karet dan Plastik, 29(1), pp. 13-20. 